\title{
Analysis of hull, propeller and engine interactions in regular waves by a combination of experiment and simulation
}

\author{
M. Hossein Ghaemi ${ }^{1}$ (D) Hamid Zeraatgar ${ }^{2}$
}

Received: 4 December 2019 / Accepted: 2 May 2020 / Published online: 27 May 2020

(c) The Author(s) 2020

\begin{abstract}
The goal of this study is to investigate ship propulsion system dynamics under sea wave conditions by including the interaction of hull, propeller, and engine. A mathematical ship propulsion system model was made and the related computer code was developed. To get the results as close as possible to real conditions, measured data for physical models, including the ship's resistance in calm and sea waves and propeller performance, were implemented in the model. For a diesel engine, performances provided by the manufacturer were used. The wave force time series, as exciting force, changed the propulsion system state from steady to transient. It activated system variables including ship's speed, advance number, propeller and engine torque, propeller and engine rotational speeds, effective and generated powers, and net thrust. The analysis was performed for a container ship for two regular waves. Using the developed computer code, the ship's speed and system variables, as well as the consumed fuel and the voyage distance, were calculated and compared with the calm water condition. The voyage mode was set on constant rotational engine speed implementing a P-action governor with fuel rate and engine torque limiters. The outcomes of the research explain the influence of the governor and its limiters on fuel consumption, identify the nonlinear impact of sea waves on propeller characteristics, and underline the effect of voyage mode on system response and the consumed fuel. The results also show that the conventional method for calculating speed reduction based on the added resistance is not capable of justifying the system's dynamic behaviour.
\end{abstract}

Keywords Hull-propeller-engine interaction · Ship propulsion system · Sea waves, added resistance

\section{Introduction}

Ship propulsion systems are initially designed by considering hull-propeller-engine interaction in calm water at steady forward speed conditions. Additionally, up to $25 \%$ extra power may be added to the steady condition power requirement to compensate for added resistance from sea waves. Furthermore, sea waves cause fluctuation of resistance and thrust, which results in ship and propeller speed fluctuations. However, in practice, hull-propeller-engine interaction in an unsteady fluctuation state is not taken into consideration. Moreover, sea waves, varying in state and space and

M. Hossein Ghaemi ghaemi@pg.edu.pl

1 Faculty of Ocean Engineering and Ship Technology, Gdańsk University of Technology, Gdańsk, Poland

2 Department of Maritime Engineering, Amirkabir University of Technology, Tehran, Iran causing unsteady motions, have no place in the analysis of hull-propeller-engine interaction in the ship design process.

In the literature, several attempts have been made to study the dynamic interaction between hull, propeller and engine. This kind of study may result in a better understanding of the real condition of propulsion system sub-elements, such as the engine and propeller, which is important for their design and selection. It may also lead to better engine control for enhancing overall total ship performance and the comfort of crews and passengers and, more importantly, to reduce fuel consumption and emissions. The latter means decreasing greenhouse gas emission during ship operation.

Schulten [1] considered the interaction of diesel engine, ship and propeller during manoeuvring in calm water conditions. Lanchukovsky [2] distinguished the ship performances in moderate and rough seas. He stated that in moderate sea waves, the engine speed and torque fluctuate due to the fluctuating inflow velocity into the propeller disk caused by wave orbital velocity and ship motions. While in rough seas, 
large ship motions cause propeller emergence, which in turn causes the loss of propeller torque.

Bondarenko and Kashiwagi [3] studied the dynamic behaviour of a ship propulsion plant in actual seas. They concluded that a conventional governor cannot effectively control the ship propulsion plant in the case of large and abrupt propeller torque losses. This fact necessitates developing a new control algorithm that can effectively mitigate disturbances caused by the propeller racing.

Kayano et al. [4] studied the effect of wind and waves on propulsion system performance using full-scale tests. They noticed that the real delivered power in waves is higher than the calculated, while the real propulsion system efficiency is lower than the value obtained by calculations. These discrepancies with the conventional method require a new calculation method.

Tanizawa et al. [5] studied self-propulsion tests in waves to estimate fuel consumption when the ship is equipped with a controllable pitch propeller. To do so, they simulated a propulsion system in unsteady conditions.

Theotokatos and Tzelepis [6] analysed fuel consumption and emitted gases by ship engine through a simulating model using hull-propeller-engine interaction. They concluded that the combined engine-propeller-ship modelling can be used for mapping the engine and emission parameters and supporting the analysis of the propulsion system behaviour over the entire ship operating envelope.

Taskar et al. [7] have used a coupled model of enginehull-propeller with a method to estimate wake in waves. They concluded that significant changes in the propulsion performance in unsteady states have been observed in the presence of waves as compared to steady-state operation. It has been shown that engine-propeller response i.e. power, propeller rotational speed and torque fluctuations can be obtained through a coupled simulation model only by using realistic engine and propeller models.

Tokgoz et al. [8] considered two propellers under behind hull conditions at head regular waves by experimental tests and numerical simulation. Their results show that the propeller thrust in regular waves has harmonic oscillation at encounter frequency about its mean value in calm water. The oscillation amplitude is relatively small. However, as soon as the propeller blade closes with the water surface, ventilation occurs and the propeller thrust radically drops.

Mizythras et al. [9] studied an engine and its elements performances in acceleration mode in rough seas using hullpropeller-engine interactions. Through the analysis, it was revealed that the presence of the engine governor limiters and their application timing significantly affect the overall ship performance.

Kitagawa et al. [10] have successfully identified both by mathematical modelling and experiment the components of wave orbital motion in propeller effective inflow velocity and analysed its effects on load fluctuations of a ship main engine in waves. To do so, they have benefited an extensive free-running model tests in head waves which has been previously conducted by the same authors. A servo-drive has been applied, which controlled in such a way to perform real diesel engine dynamic. The model forward speed is kept fixed.

Zeraatgar and Ghaemi [11] developed a simulation model by which they included the dynamic interaction of hullpropeller-engine. They employed a code for simulating fuel consumption as an objective function for ship accelerating manoeuvres in calm water conditions. They proved that reducing fuel consumption and harmful emissions are possible by modifying the control strategy and governor parameters.

Considering the above-mentioned literature, the hullpropeller-engine interaction simulation in real sea conditions and shipmaster ordered manoeuvres has been the main objective of the studied literature. Each study, of course, focused on different aspects. It seems that this research topic is under development and must proceed rapidly, particularly due to the increasing importance of fuel consumption and emissions reduction. Table 1 summarizes the reviewed literature and the following is concluded:

- The ship hull-propeller-engine interaction in sea waves including wave force acting on the hull, propeller wake fluctuation with thrust and torque oscillations in combination to diesel engine dynamic cannot be fully modelled neither by numerical simulation nor by experimental model test.

- The hull-propeller simulation in waves such as selfpropulsion test can be conducted both numerically and experimentally.

- The propeller-engine simulation in waves has also been worked out taking into consideration propeller torque and thrust fluctuation.

- The hull-propeller-engine interactions in waves are challenged. However, only the wave force mean value, added resistance, has been taken into account.

Referring to Table 1 and considering the previous researches, it can be concluded that analysis of the interaction of hull, propeller and engine in waves was mainly limited to considering the effect of the mean added resistance force [9]. The goal and contribution of this study are to replace the mean added resistance by time trace of wave force fluctuations in the problem of interaction of hull, propeller and engine. Additionally, the methodology of combining simulation with usually available experiments allows the shipmaster's order to be better managed regarding the time trace of fuel injection to the engine. As a result, the inclusion of time trace of wave force fluctuations and fuel injection can be mentioned as a major contribution and a step forward in this area of research. 
Table 1 Summary of the reviewed literature and their limiting assumptions

\begin{tabular}{llll}
\hline Author & Coupled systems & Employed method & Environment \\
\hline Schulten [1] & Hull- propeller-engine & Simulation & Calm water \\
Lanchukovsky [2] & Engine & simulation & Waves \\
Bondarenko and Kashiwagi [3] & Hull-propeller-engine & $\begin{array}{l}\text { Simulation mostly concerns propeller wake flow in wave in mean } \\
\text { added resistance }\end{array}$ & Wave \\
Kayano et al. [4] & Hull-propeller-engine & Full scale field study & Wind and waves \\
Tanizawa et al. [5] & Hull-propeller-engine & Simulation plus model test & Waves \\
Theotokatos and Tzelepis [6] & Propeller-engine & Simulation many regression coefficients are employed and time- & Waves \\
& & varying wave force was ignored & Waves \\
Taskar et al. [7] & Propeller-engine & Simulation & Waves \\
Tokgoz et al. [8] & Hull-propeller & Simulation and model test & Waves \\
Mizythras et al. [9] & Hull-propeller-engine & Simulation & Waves \\
Kitagawa et al. [10] & Propeller-engine & Free-running model tests in waves including simulated diesel engine & Calm water \\
Zeraatgar and Ghaemi [11] & Hull-propeller-engine & Simulation plus model test & \\
\hline
\end{tabular}

Considering Taskar et al. study [7], if the waves are moderate and propeller is not ventilated the torque and thrust oscillation amplitude is low (less than $10 \%$ of its mean value) and reduction of their mean values are relatively low, as well. For the sake of simplicity, the oscillation of the thrust and torque as well as change of their mean values in comparison with the huge oscillation of wave force are disregarded in this study. The paper deals to the problem under the condition of low or moderate sea waves, where the propeller always remains submerged (not ventilated). The wave force oscillation is the dominant parameter of the coupled dynamic response of hull, propeller and engine.

In this research, a study on engine performance in regular waves was carried out by combining experiments and simulation. The mathematical model describes the interaction between hull, propeller and engine. The simulation is capable of including major dynamic effects induced by sea waves and/or ordered by the shipmaster in the form of a set point of engine speed change. A computer code for the simulation model was developed and a case study was conducted.

The case study is a Series 60 ship model, which was tested in calm water and in regular waves for resistance measurements. A B-Wageningen type propeller model, designed for the considered ship model, was also tested in the towing tank under open water conditions and its hydrodynamic characteristics have been recorded. Based on the tested model, a $182 \mathrm{~m}$ long container ship was designed by scaling up the hull and propeller models and then her characteristics were calculated by extrapolating the results of the model tests. A proper twostroke diesel engine, which is capable to run the ship under desired service speed at calm water conditions, was assigned to the ship. The ship is supposed to face regular waves and the resistance is a function of time. Ship speed, propeller rotational speed, advance ratio, propeller torque and thrust, and engine variables were calculated and simulated in the time domain.

\section{Hull, propeller and engine individual and coupled dynamics in sea waves}

When a ship is in the calm water condition on a straight path, the hull, propeller and engine are operating in steady condition. As soon as a change is made on the ship path (for example by turning the rudder), ship speed (for example by changing the set point of engine speed) or ship resistance (for example by changing the sea condition from calm to wavy) occurs, the hull, propeller and engine enter the acceleration mode. The interactions between hull, propeller and engine further magnify the dynamic reactions of the ship and her subsystems, simultaneously.

In this study, the disturbance initiated by regular sea waves was considered as the exciting signal of the system. A ship in regular waves faces a total resistance that fluctuates by large amplitudes. The amplitude of total resistance in low and moderate wave heights is large and changes from against ship movement to in favour of ship movement during one encounter period. In spite of the regular nature of the exciting signal, the response does not necessarily have a regular form because of nonlinearities that may happen in different elements of the ship's subsystems. Certainly, the mean value of total resistance is larger than the calm water resistance and depends on the wave height, period, ship speed and its heading in respect to wave heading. The ship's speed during an encounter period oscillates about the mean speed value versus time. Clearly, if the engine operating point is maintained as a constant, then the mean speed in waves will be lower than in calm water. Meanwhile, the engine torque and propeller torque and thrust are dynamically changed depending on their performance characteristics. The rotational speed of the propeller and engine are adjusted accordingly. Simulation of the dynamic behaviour of the hull, propeller and engine provides data for better understanding the phenomena and may be utilized for monitoring the subsystems 
of engine, shaft line and other elements of the ship propulsion system.

\subsection{Principles of hull, propeller and engine interactions in regular waves}

Hull, propeller and diesel engine dynamics are interrelated when sea waves cause ship acceleration. The following two coupled equations present the relationship between them:

$\left\{\begin{array}{l}-R_{\mathrm{T}}(u(t))-R_{\mathrm{a}}(t)+T_{n}(t)=\left(\Delta+x_{\dot{u}}\right) \dot{u}(t) \\ Q_{\mathrm{E}}(t)-Q_{\mathrm{P}}(t)=\left(I_{\mathrm{P}}+I_{\mathrm{Pa}}+I_{\mathrm{E}}+I_{\mathrm{S}}\right) \dot{\omega}(t)\end{array}\right.$,

where $R_{\mathrm{T}}(u)$ is the ship resistance as a function of ship speed in $x$ direction, $R_{\mathrm{a}}(t)$ is total wave force in $x$ direction, mean value as the added resistance and time varying as a longitudinal force in $x$ direction, $T_{n}(t)$ is the net thrust generated by the propeller and is a function of time, $\Delta$ is ship mass, $x_{\dot{u}}$ is ship added mass in $x$ direction, $\dot{u}$ is ship acceleration in $x$ direction, $Q_{\mathrm{E}}(t)$ is the engine delivered torque, $Q_{\mathrm{P}}(t)$ is the propeller torque demand, $I_{\mathrm{P}}$ is the propeller moment of inertia, $I_{\mathrm{Pa}}$ is the propeller added moment of inertia, $I_{\mathrm{E}}$ is the engine moment of inertia, $I_{S}$ is the shaft moment of inertia and $\dot{\omega}(t)$ is the propeller angular acceleration.

The system of Eq. 1 should be solved numerically in the time domain.

\subsection{Hull resistance in waves}

\subsubsection{Resistance in calm water in acceleration mode}

Hull resistance in calm water in acceleration mode is composed of conventional hull resistance and ship added mass in $x$ direction induced force. They are formulated as follows:

$R_{\mathrm{t}}(t)=R_{\mathrm{T}}(u(t))+x_{\dot{u}} \dot{u}(t)$

$R_{\mathrm{T}}(t)=C_{\mathrm{T}} \times \frac{1}{2} \rho u^{2}(t) \times A_{s}$,

where $C_{\mathrm{T}}$ is the total resistance coefficient. The ship added mass in $x$ direction is a function of its breadth to length ratio and is typically taken as 5-10 per cent of a ship's mass [12].

\subsubsection{Total wave force on the hull in waves at a steady speed}

A ship in waves confronts extra time-varying force and its mean value called added resistance, which is principally generated by the pressure change around the hull. Researchers and designers usually use its mean value in calculations. It is approximately a second-order function of wave amplitude [13]. In this study, the wave force-time history is a prerequisite for the simulation as an input or exciting signal. A ship operating in the steady calm water condition facing the waves dynamically reacts and follows the wave force oscillations [14]. Sea waves not only impose oscillations on ship forward speed but also affects the propeller rotational speed and makes it oscillate the same as wave force.

The wave force time series are either approximated by numerical methods or by the model test results. In the latter case, the total resistance of the model in a given regular wave as a function of time, $R_{\mathrm{tm}}(t)$, is recorded. Knowing the total resistance of the model in calm water, $R_{\mathrm{Tm}}$, the time history of the wave force of the model, $R_{\mathrm{am}}(t)$, at constant speed is calculated as:

$R_{\mathrm{am}}(t)=R_{\mathrm{tm}}(t)-R_{\mathrm{Tm}}(u)$,

where the subscript $m$ refers to the model.

Following the Froude's Law of Similitude, the time history of the wave force, $R_{\mathrm{a}}(t)$, and total resistance in waves, $R_{\mathrm{t}}(t)$, at constant speed can be calculated as follows:

$R_{\mathrm{a}}(t)=\lambda_{\mathrm{m}}^{3} \times R_{\mathrm{am}}(t)$

$R_{\mathrm{t}}(t)=R_{\mathrm{T}}(u(t))+R_{\mathrm{a}}(t)$,

where $\lambda_{\mathrm{m}}$ stands for the ratio of ship length to model length.

\subsubsection{Total ship resistance in waves at acceleration mode}

The total resistance of the ship in waves in the acceleration mode is as follows:

$R_{\mathrm{t}}(t)=R_{\mathrm{T}}(u)+x_{\dot{u}} \dot{u}(t)+R_{\mathrm{a}}(t)$.

\subsection{Propeller performance in waves}

A propeller in waves has unsteady rotational speed, torque and thrust. Open water propeller hydrodynamic characteristics at steady rotational speed are available based on the model test results. The propeller torque and thrust are simulated based on its open water performances at steady conditions, taking into account its instantaneous advance number.

\subsubsection{Propeller performance in calm water in acceleration mode}

A propeller at instantaneous rotational speed, $n(t)$ and advance speed, $u_{\mathrm{A}}(t)$, has thrust $T(t)$, and torque $Q_{\mathrm{P}}(t)$, which vary in time and can be approximated by propeller open water characteristics as follows: 
$J_{\mathrm{A}}(t)=\frac{u_{\mathrm{A}}(t)}{D_{\mathrm{p}} n_{\mathrm{P}}(t)}$

$T(t)=K_{\mathrm{T}}\left(J_{\mathrm{A}}(t)\right) \rho n_{\mathrm{P}}^{2}(t) D_{\mathrm{P}}^{4}$

$Q_{\mathrm{P}}(t)=K_{\mathrm{Q}}\left(J_{\mathrm{A}}(t)\right) \rho n_{\mathrm{P}}^{2}(t) D_{\mathrm{P}}^{5}$,

where $K_{\mathrm{T}}(t)$ is thrust coefficient, $K_{\mathrm{Q}}(t)$ is the propeller torque coefficient, $\rho$ is the water density, $n_{\mathrm{P}}$ is the rotational speed of propeller (rps) and $D_{\mathrm{P}}$ is the propeller diameter. The relationship between the advance velocity and ship speed is defined by the mean wake fraction, $w(t)$, as follows:

$u_{\mathrm{A}}(t)=u(t)(1-w(t))$.

The net thrust, $T_{n}(t)$, depends on thrust deduction factor, $t_{T}(t)$, as follows:

$T_{n}(t)=T(t)\left(1-t_{\mathrm{T}}(t)\right)$.

The wake fraction and thrust deduction factor are variable in time in sea waves. For the sake of simplicity, a quasisteady concept can be applied, assuming they are equal to the same values as in the steady-state, and determined based on empirical formulae, e.g.:

$w=0.45 C_{\mathrm{p}}-0.05$ (Robertson)

$t_{\mathrm{T}}=0.5 C_{\mathrm{p}}-0.12$ (Hecker).

As far as required propeller torque in acceleration mode is concerned, additional torque due to the added moment of inertia of the propeller, $I_{\mathrm{Pa}}$, should also be included:

$Q_{\mathrm{E}}(t)=K_{\mathrm{Q}}\left(J_{\mathrm{A}}(t)\right) \rho n_{\mathrm{P}}^{2}(t) D_{\mathrm{P}}^{5}+\left(I_{\mathrm{P}}+I_{\mathrm{Pa}}+I_{\mathrm{E}}+I_{\mathrm{S}}\right) \dot{\omega}_{\mathrm{P}}(t)$,

where $\dot{\omega}_{\mathrm{P}}(t)$ is the propeller rotational acceleration in $\mathrm{rad} / \mathrm{s}^{2}$.

Propeller moment of inertia is calculated as follows:

$I_{\mathrm{P}}=\frac{D_{\mathrm{P}}^{2}}{K_{\mathrm{p}}} \times m_{\mathrm{P}}$,

where $m_{\mathrm{P}}$ is the propeller mass and $K_{\mathrm{P}}$ is a factor approximated between 19 and 28, typically reported as 23 . In reality, the propeller added moment of inertia can be approximated as:

$I_{\mathrm{Pa}}=K_{\mathrm{a}} \times I_{\mathrm{P}}$,

where $K_{a}$ is suggested to be $0.25-0.30$ [15] or $0.25-0.50$ [16].

\subsubsection{Propeller performance in regular waves}

Studies on propeller performance in waves have shown that inflow velocity, thrust and torque oscillate regularly with relatively low amplitude at the encounter wave frequency [8]. As soon as it closes to the free surface and/ or emerges from the water, the thrust and torque forces radically change.

For the sake of simplicity, the oscillation of the thrust and torque as well as change of their mean values in comparison with the huge oscillation of wave force are disregarded. it is assumed that the case study has low heave and pitch motions hence propeller emergence, ventilation, does not happen. Therefore, the above presented calm water condition (2.3.1) and rotational acceleration make the basis of propeller performance estimation in waves.

It should be mentioned that there are two additional wave-induced phenomena, which have to be included in the analysis of coupled dynamic performances of hull, propeller, engine interactions. They are: (a) surge motion and (b) wave orbital motion. They may be included in the calculation of flow mean velocity entering into the propeller disc as follows [10]:

$$
\begin{aligned}
u_{\mathrm{A}}(t)= & {\left[u(t)-\omega_{\mathrm{e}} \bar{\eta}_{1} \sin \left(\omega_{e} t-\varepsilon_{1}\right)\right](1-w(t)) } \\
& +\bar{u}_{\mathrm{PW}} \cos \left(\omega_{\mathrm{e}} t-k \times x_{\mathrm{p}} \cos \chi\right),
\end{aligned}
$$

where $\bar{\eta}_{1}$ and $\varepsilon_{1}$ are amplitude and phase-lag of surge motion, $\bar{u}_{\mathrm{PW}}$ is the amplitude of wave orbital inflow velocity, $k$ is the wave number, $x_{\mathrm{P}}$ is the location of the propeller in respect to the origin of the coordinate system and $\chi$ is the ship heading angle in respect to the wave direction.

Kitagawa et al. have clearly showed that if $\lambda / L$ (wave length over ship's length) is less than 1 , then the surge speed effect is almost negligible. For both considered cases in this study, $\lambda / L$ is less than 1 . As far as wave orbital inflow velocity is concerned, it was also included in the analysis and results shew that it influences mainly the engine torque and power, and has some effects on the propeller speed, thrust and torque of the propeller. However, for the sake of simplicity and because of the objective of this paper, it is also excluded from the presented results. It should be included in the future analysis and a separate study is needed.

Moreover, in the case of wind force, the simulation model has capability to take into account the mean and time-varying wind force while it can be added in the future work. 


\subsection{Diesel engine performance}

\subsubsection{Diesel engine performance in steady conditions}

The diesel engine is modelled using a simplified mathematical model by a first-order transfer function with a delayed response [17]:

$\frac{Q_{\mathrm{E}}(s)}{X_{\mathrm{f}}(s)}=e^{-\tau \times s} \times \frac{K_{\mathrm{E}}}{1+T_{\mathrm{E}} s}$,

which can be represented by the following differential equation:

$T_{\mathrm{E}} \dot{Q}_{\mathrm{E}}(t-\tau)+Q_{\mathrm{E}}(t-\tau)=K_{\mathrm{E}} \times X_{\mathrm{f}}(t)$.

In Eqs. (19) and (20), $X_{\mathrm{f}}$ is the fuel index or fuel rack based on which the fuel mass flow rate $[\mathrm{kg} / \mathrm{s}]$ is known, $\tau$ is the response delay [s], $K_{\mathrm{E}}$ is a gain and $T_{E}$ is the time constant [s]. If $X_{\mathrm{f}}$ is the fuel index, then its value at the nominal engine design point is 1 . The time delay and time constant can be calculated in relation to the time between two successive ignitions in each cylinder for a two-stroke diesel engine, which is $2 \pi / \omega_{\mathrm{E}}$, where $\omega_{\mathrm{E}}$ is the angular velocity of the engine shaft $[\mathrm{rad} / \mathrm{s}]$. For an engine with $Z_{\mathrm{E}}$ cylinders, the time delay is determined as half of the time needed for two successive ignitions in the whole engine:

$\tau=\frac{1}{2} \times \frac{2 \pi}{Z_{\mathrm{E}} \times \omega_{\mathrm{E}}}$.

The time constant should reflect the inertial behaviour of the engine for generating torque after receiving the necessary fuel for combustion and, therefore, is approximated as $\mathbf{8 5 - 9 5 \%}$ of the time between two successive ignitions in one cylinder. Here, the average is considered:

$T_{\mathrm{E}}=0.9 \times \frac{2 \pi}{\omega_{\mathrm{E}}}$

The gain value can be determined based on the steady-state characteristics of the selected engine as follows:

$K_{E}=\frac{Q_{E}\left(n_{E 0}\right)}{X_{f}\left(n_{E 0}\right)}$ where $n_{\mathrm{E} 0}$ represents revolution rate [rpm] of the engine shaft at a given steady-state condition, e.g. at Normal Continuous Rating (NCR). A detailed diesel engine model can be found in Ghaemi [18].

The engine is assumed to be equipped with a governor that keeps the shaft rotational speed at a constant level with respect to the operating point of the engine and the command signal (see Fig. 1).

It is assumed that the sea waves do not directly influence the engine performance, while they impose time variation of engine performance through changing the propeller torque and rotational speed. Therefore, the above-given engine performance model is preserved in sea waves conditions as well.

\section{Case study, simulation and results}

For simulation purpose, a computer code using MATLABSIMULINK was developed based on the mathematical model presented in the previous sections. The block diagram of the simulation model is given in Fig. 2. It was applied for a ship with a Series 60 hull form for which the calm water resistance and time series of wave force were determined based on the model tests. The open water propeller performances were also available based on propeller model test results.

A two-stroke low-speed diesel engine was selected to drive the propeller. The engine was selected corresponding to the required power, considering the open water and relative rotative efficiencies of the propeller, hull effectiveness and shaft and mechanical efficiencies, as well as sea and engine margins.

\subsection{Ship specifications}

The current study is a continuation of research previously presented by Zeraatgar and Ghaemi [11] and the same ship was selected here. The calculation was performed for a container ship with a Series 60 hull-form having a block coefficient of 0.60 . The ship specifications are given in Table 2 .

A 4.58-m long model was tested in NIMALA (National Iranian Marine Laboratory) for a conventional resistance

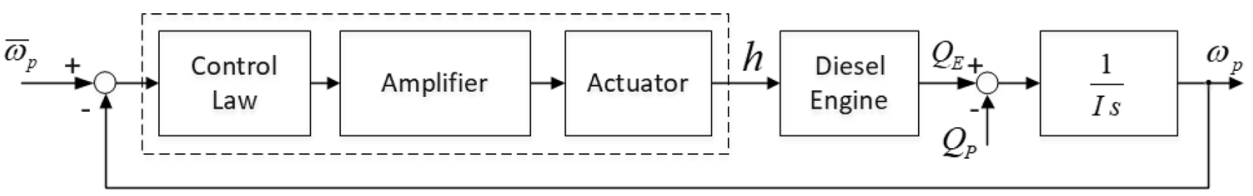

Fig. 1 Simplified engine-propeller block diagram, where $\overline{\omega_{\mathrm{P}}}$ and $\omega_{\mathrm{P}}$ are the command and controlled shaft angular velocity, respectively, $h$ is the fuel rate, $Q_{\mathrm{E}}$ is engine torque, $Q_{\mathrm{P}}$ is propeller torque and $I$ stands for an overall moment of inertia including propeller, added, engine and shaft moments of inertia 


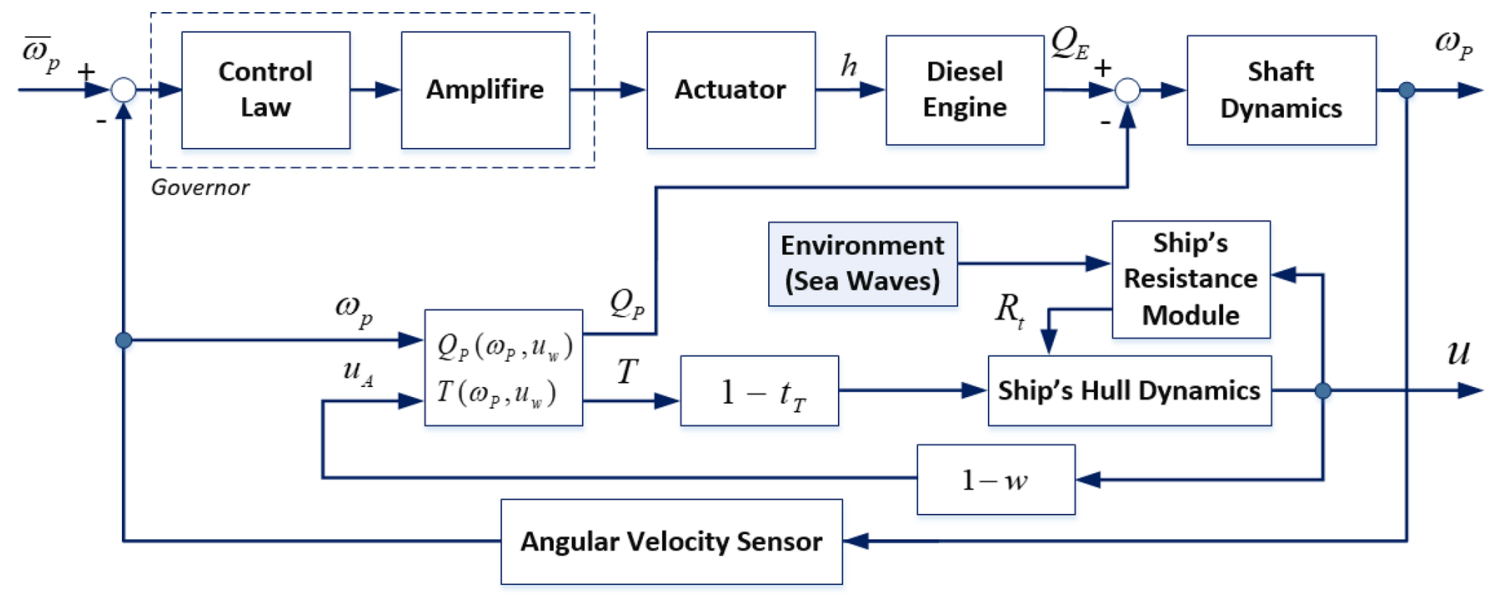

Fig. 2 The block diagram of the simulation model. For a given environment condition, ship resistance is estimated using the measured data. The wave force is an input. Propeller rotational speed and ship speed are the main outputs. The control system is designed to achieve a constant rotational speed

Table 3 Ship calm water resistance [11]

\begin{tabular}{lrllr}
\hline No. & $u[\mathrm{~m} / \mathrm{s}]$ & $F n$ & $C_{\mathrm{t}}$ & $R_{\mathrm{t}}[\mathrm{kN}]$ \\
\hline 1 & 0.000 & 0.000 & 0.0000000 & 0.000 \\
2 & 1.000 & 0.023 & 0.0017700 & 5.260 \\
3 & 2.000 & 0.047 & 0.0017700 & 21.040 \\
4 & 3.000 & 0.070 & 0.0017700 & 47.340 \\
5 & 4.000 & 0.094 & 0.0017760 & 84.170 \\
6 & 5.130 & 0.120 & 0.0017760 & 138.430 \\
7 & 5.984 & 0.140 & 0.0018060 & 191.526 \\
8 & 6.839 & 0.160 & 0.0018070 & 250.361 \\
9 & 7.694 & 0.180 & 0.0018060 & 316.960 \\
10 & 8.549 & 0.200 & 0.0018297 & 396.061 \\
11 & 9.404 & 0.220 & 0.0019500 & 510.911 \\
12 & 10.259 & 0.240 & 0.0019619 & 611.559 \\
13 & 10.686 & 0.250 & 0.0020545 & 694.845 \\
14 & 11.114 & 0.260 & 0.0024144 & 883.286 \\
15 & 11.969 & 0.280 & 0.0030059 & 1275.390 \\
16 & 12.396 & 0.290 & 0.0033275 & 1514.370 \\
17 & 12.824 & 0.300 & 0.0021962 & 1683.440 \\
18 & 13.679 & 0.320 & 0.0035106 & 1945.550 \\
\hline
\end{tabular}

The prime mover is a MAN-B\&W 8S65ME-C8.5 lowspeed diesel engine. The Service Maximum Continuous Rating (SMCR) was set at 19,433 kW @ 92.8 RPM. The steady-state performance of the engine is given in Table 5 .

\subsection{Wave force in regular waves}

The model was tested in several regular and one irregular wave and total resistance, heave and pitch motions were recorded in the time domain. However, due to the very large instantaneous wave force of the model, the dynamometer was overloaded for several cases. Finally, two regular wave datasets were in the range of the dynamometer capacity and
Table 4 Propeller specifications [11]

\begin{tabular}{ll}
\hline Type & $\begin{array}{l}\text { B-Wageningen } \\
\text { fixed pitch pro- } \\
\text { peller }\end{array}$ \\
\hline Diameter & $7.590[\mathrm{~m}]$ \\
Number of blades & 5 \\
Area ratio & 0.5808 \\
Pitch ratio & 1.00 (at full pitch) \\
\hline
\end{tabular}




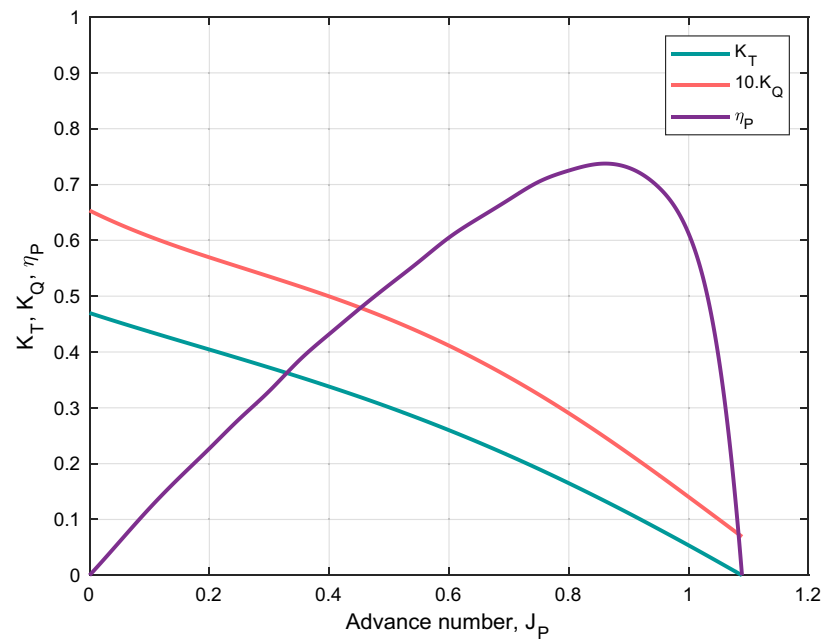

Fig. 3 The propeller open water model test results [11]

Table 5 MAN-B\&W 8S65ME-C8.5 Engine performance [11]

\begin{tabular}{lcllll}
\hline $\begin{array}{l}\text { Load } \\
\text { OP }[\%]\end{array}$ & $\begin{array}{l}\text { Power } \\
{[\mathrm{kW}]}\end{array}$ & $\begin{array}{l}\text { Speed } \\
{[\mathrm{RPM}]}\end{array}$ & $\begin{array}{l}\text { SFOC } \\
{[\mathrm{g} / \mathrm{kWh}]}\end{array}$ & $\begin{array}{l}\text { FR } \\
{[\mathrm{kg} / \mathrm{s}[}\end{array}$ & $\begin{array}{l}\text { Engine eff. } \\
{[-]}\end{array}$ \\
\hline 10 & 1943 & 43.1 & 188.0 & 0.101468 & 0.4485 \\
15 & 2915 & 49.3 & 178.0 & 0.144131 & 0.4736 \\
20 & 3887 & 54.3 & 174.0 & 0.187872 & 0.4845 \\
25 & 4858 & 58.5 & 172.0 & 0.232104 & 0.4902 \\
30 & 5830 & 62.1 & 170.0 & 0.275306 & 0.4959 \\
35 & 6802 & 65.4 & 169.0 & 0.319316 & 0.4989 \\
40 & 7773 & 68.4 & 167.5 & 0.36166 & 0.5033 \\
45 & 8745 & 71.1 & 166.1 & 0.403485 & 0.5076 \\
50 & 9717 & 73.7 & 164.9 & 0.445093 & 0.5113 \\
55 & 10688 & 76.0 & 163.7 & 0.486007 & 0.5150 \\
60 & 11660 & 78.3 & 162.6 & 0.526643 & 0.5185 \\
65 & 12,631 & 80.4 & 161.7 & 0.567342 & 0.5214 \\
70 & 13,603 & 82.4 & 161.1 & 0.608734 & 0.5233 \\
75 & 14,575 & 84.3 & 161.3 & 0.653041 & 0.5227 \\
80 & 15,546 & 86.1 & 161.7 & 0.698275 & 0.5214 \\
85 & 16,518 & 87.9 & 162.3 & 0.744687 & 0.5195 \\
90 & 17,490 & 89.6 & 163.1 & 0.792394 & 0.5169 \\
95 & 18,461 & 91.2 & 164.2 & 0.842027 & 0.5135 \\
100 & 19,433 & 92.8 & 165.5 & 0.893378 & 0.5094 \\
\hline & & & & &
\end{tabular}

were then used for the current study. The specifications of these regular waves are shown in Table 6.

Not only the wave height but also the encounter wave frequency resulted from incident wave frequency, ship speed and its direction have a crucial effect on the interaction of hull, propeller and engine. Due to limited added resistance data, the effect of encounter frequency is not included in the analysis.
Table 6 Specifications of two regular waves selected for the current study

\begin{tabular}{llll}
\hline Case & $\begin{array}{l}\text { Wave height, } H \\
{[\mathrm{~cm}]}\end{array}$ & $\begin{array}{l}\text { Wave period, } \\
T[\mathrm{~s}]\end{array}$ & Wave length $[\mathrm{m}]$ \\
\hline $\mathrm{A}$ & 4 & 1.13 & 1.67 \\
$\mathrm{~B}$ & 8 & 1.60 & 4.00 \\
\hline
\end{tabular}

The total resistance of the model in waves was recorded and, by following Eq. 5, a time series of wave force of the model was deducted. Next, based on Eqs. 6 and 7, the total resistance of the ship was calculated. Figures 4 and 5 show the total resistance of the ship for two cases: Case A and Case B, respectively.

\subsection{Simulation and results}

\subsubsection{Assumptions}

The governor coefficients have a great impact on system behaviour. They also affect the ship speed and propeller rotational speed, as accelerations. For presentation purposes and to be able to compare the results, the governor was optimised using the Ziegler-Nichols method by selecting a simple P-action type for which the gain value was set to 14 . In reality, the majority of marine governors are equipped also with an integral part and they are PI or PID-action types. The reason for which a P-action governor is selected here is to eliminate the influence of an integral part of the governor on the fuel consumption to be sure the change of fuel consumption is mainly related to the sea waves.

The simulation was conducted in three phases. At the first phase, 0-500 s, the motion dynamics were simulated under calm water conditions to reach steady-state at the nominal point. In the second phase, 500-900 s, the wave force from regular waves in combination with the calm water resistance imposes a dynamic force to the hull, propeller and engine. This period is enough for all dynamic responses, such as ship speed and engine and propeller rotational speed, to pass the transient state and approach a semi-harmonic state. In the third phase, starting from $900 \mathrm{~s}$, the wave force was set to zero as the input to the code, and the ship gradually comes back to the initial steady state.

It was also assumed that the voyage mode of the ship was set to keep a constant rotational speed of the engine shaft (and consequently propeller shaft) by activating the engine governor and adjusting the command signal to a constant level for NCR. Two main limiters were also applied for the system to prevent any critical overloading of the engine. The first limits the minimum and maximum generated power (from $10 \%$ of NCR up to $20 \%$ higher than NCR) and the 
Total Resistance - Case A

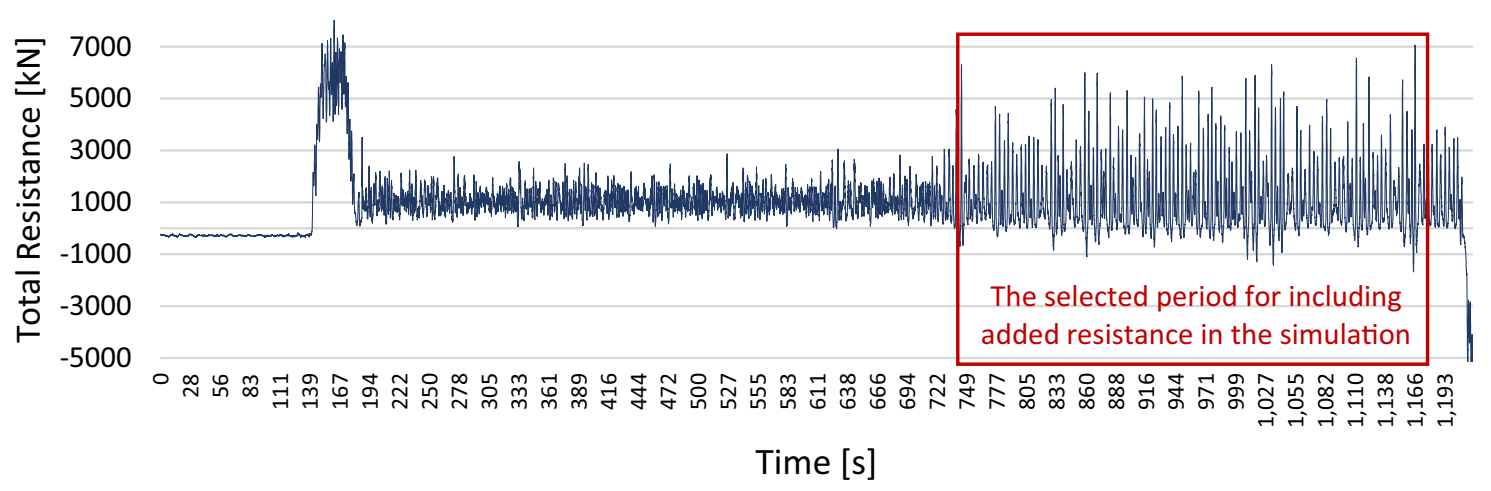

(a)

Total Resistance - Case A

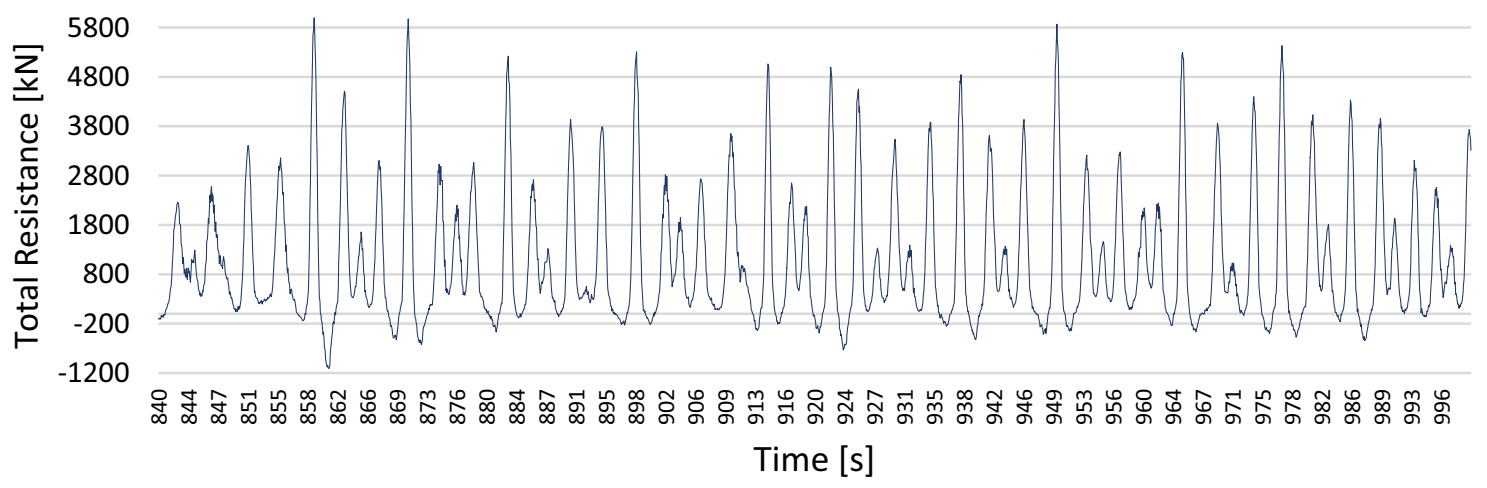

(b)

Fig. 4 Total resistance of the ship in a regular wave of $H=1.63 \mathrm{~m}$ and $T=7.23 \mathrm{~s}$ (equivalent to $H=4 \mathrm{~cm}$ and $T=1.134 \mathrm{~s}$ for the model), a whole time, $\mathbf{b}$ zoom in

second limits the minimum and maximum fuel rate (from zero up to $20 \%$ higher than related value for NCR).

\subsubsection{Results of simulation}

Figures 6, 7, 8, 9 and 10 show time traces of ship speed, shaft rotational speed, thrust and resistance and propeller and engine torques and powers for both sea waves (Case A and Case B), respectively. For better representation, a zoom-in fragment of the responses for 830-840 s is shown in the lower right corner of each figure. As it was mentioned before, the input signal is wave force.

As Fig. 6 shows, the ship has a steady speed of $11.74 \mathrm{~m} / \mathrm{s}$. As soon as she encounters waves in the form of wave force, the speed starts to fluctuate, following wave force fluctuations. As speed fluctuates, its mean value gradually reduces and approaches an almost fixed mean value. There is a considerable difference between the two wave cases. The mean value of ship speed for Case A is about $11.62 \mathrm{~m} / \mathrm{s}$, a reduction of $0.12 \mathrm{~m} / \mathrm{s}$, while it is $11.44 \mathrm{~m} / \mathrm{s}$ for Case B, a reduction of $0.30 \mathrm{~m} / \mathrm{s}$. The reason for different reductions in ship speed in the two cases can be explained by Figs. 4 and 5. The mean value and oscillation amplitude of wave force for Case B are considerably larger than Case A.

As far as propeller and engine rotational speeds are concerned, Fig. 7 shows that they have a steady speed of $9.72 \mathrm{rad} / \mathrm{s}$ before the wave force, Phase 1. As the ship encounters waves, the propeller rotational speed starts to fluctuate, and its mean value gradually reduces and approaches an almost fixed mean value. There is a difference between the two wave cases. The mean value of propeller speed for Case A is about $9.63 \mathrm{rad} / \mathrm{s}$, a reduction of $0.09 \mathrm{rad} / \mathrm{s}$, while it is $9.59 \mathrm{rad} / \mathrm{s}$ for Case $\mathrm{B}$, a reduction of $0.13 \mathrm{rad} / \mathrm{s}$. Additionally, the propeller rotational speed fluctuation has a range of amplitudes that is about $\pm 0.35 \mathrm{rad} / \mathrm{s}$ 


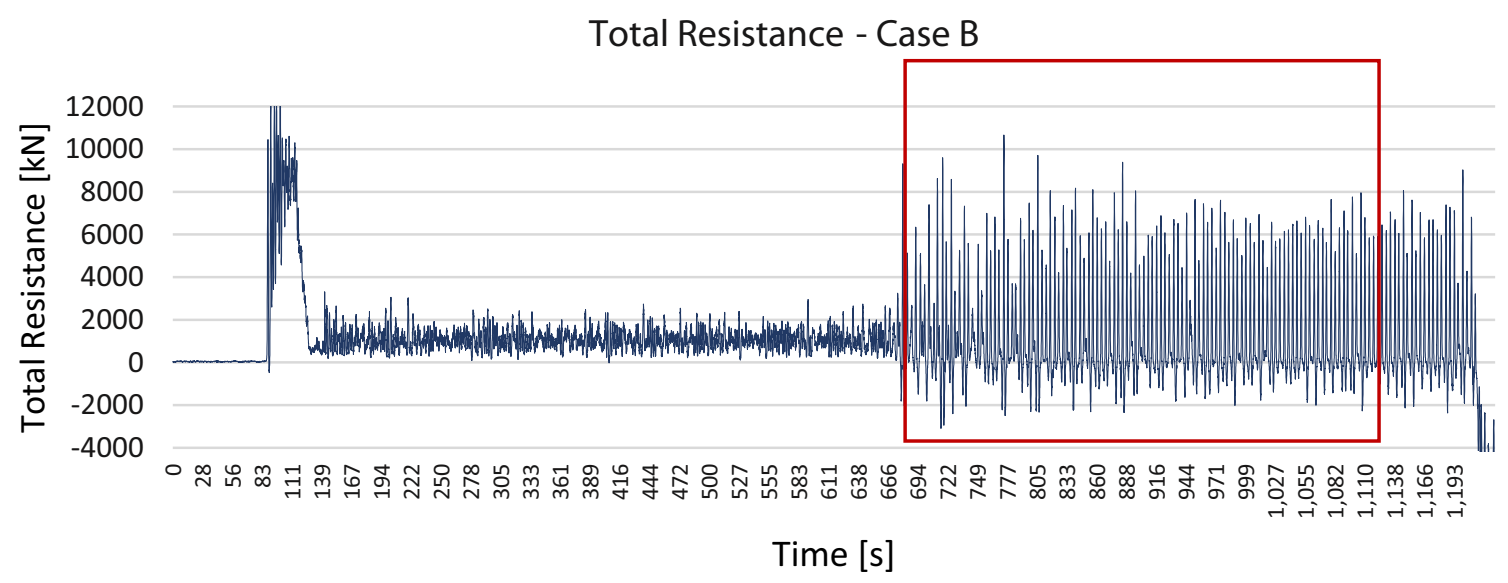

(a)

\section{Total Resistance - Case B}

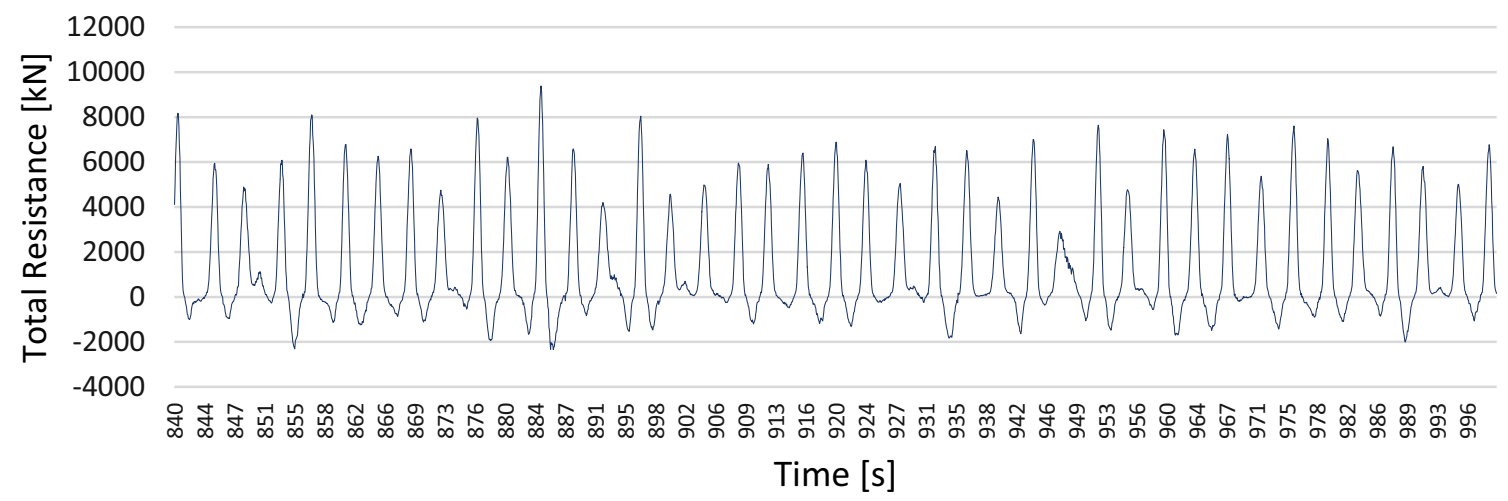

(b)

Fig. 5 Total ship resistance in a regular wave of $H=3.26 \mathrm{~m}$ and $T=10.21 \mathrm{~s}$ (equivalent to $H=8 \mathrm{~cm}$ and $T=1.6 \mathrm{~s}$ for the model)

for Case A and $\pm 0.37 \mathrm{rad} / \mathrm{s}$ for Case B. Again, the difference is related to the difference in the wave force in two cases.

Figure 8 compares net thrust and total resistance, which should balance each other at steady state. It is clear that net thrust fluctuates in response to the total resistance. However, due to the voyage mode of the ship, the governor does not permit the net thrust to follow the same variation of resistance. Practically, this is applied during real ship voyages. Therefore, the difference between the net thrust generated by the propeller and the ship's resistance is significant in unsteady states. For Case A, the variation of ship resistance in the second phase of simulation (from 500 to $900 \mathrm{~s}$ ) is in the range of $-1356 \mathrm{kN}$ (pushing the ship ahead) and $+6633 \mathrm{kN}$, while the range for net thrust is between +970 and $+1316 \mathrm{kN}$. This means, in response to the fluctuations of sea waves, which induced the total resistance span of $7989 \mathrm{kN}$, the propeller net thrust is varied only by $346 \mathrm{kN}$ and this is about $4.5 \%$ of the changes in the exciting signal. For Case B, despite the higher wave heights and larger added resistance, the variation of net thrust is still approximately in the same level $(346 \mathrm{kN})$, when the total resistance variation rises to $10,284 \mathrm{kN}$. This is $29 \%$ higher than the related value for Case A, despite doubling the wave height in Case B. Additionally, the relative variation of net thrust in relation to total resistance is only $3.3 \%$. The fact that the propeller torque directly depends on the engine torque (see Fig. 9 and compare the variation of these variables for both Cases A and B) indicates that the limitations applied by the governor have caused relatively small changes of net thrust in comparison to the ship's resistance.

The same behaviour can be observed when the propeller and engine powers are compared in Fig. 10. The span of generated power in Case A and Case B is 30,253 and $31,091 \mathrm{~kW}$, respectively, almost in a similar level, which means that the engine generated power in response to the increase of wave force in Case A and Case B is $22.5 \%$ and $18.2 \%$ in comparison to calm water conditions. This span for the effective power (required to overcome the total resistance) is 134,248 and $222,085 \mathrm{~kW}$ for Case A and Case B, 
Fig. 6 Ship speed time series for Case A and Case B in sea waves

Fig. 7 Shaft rotational speed time series for Case A and Case $\mathrm{B}$ in sea waves
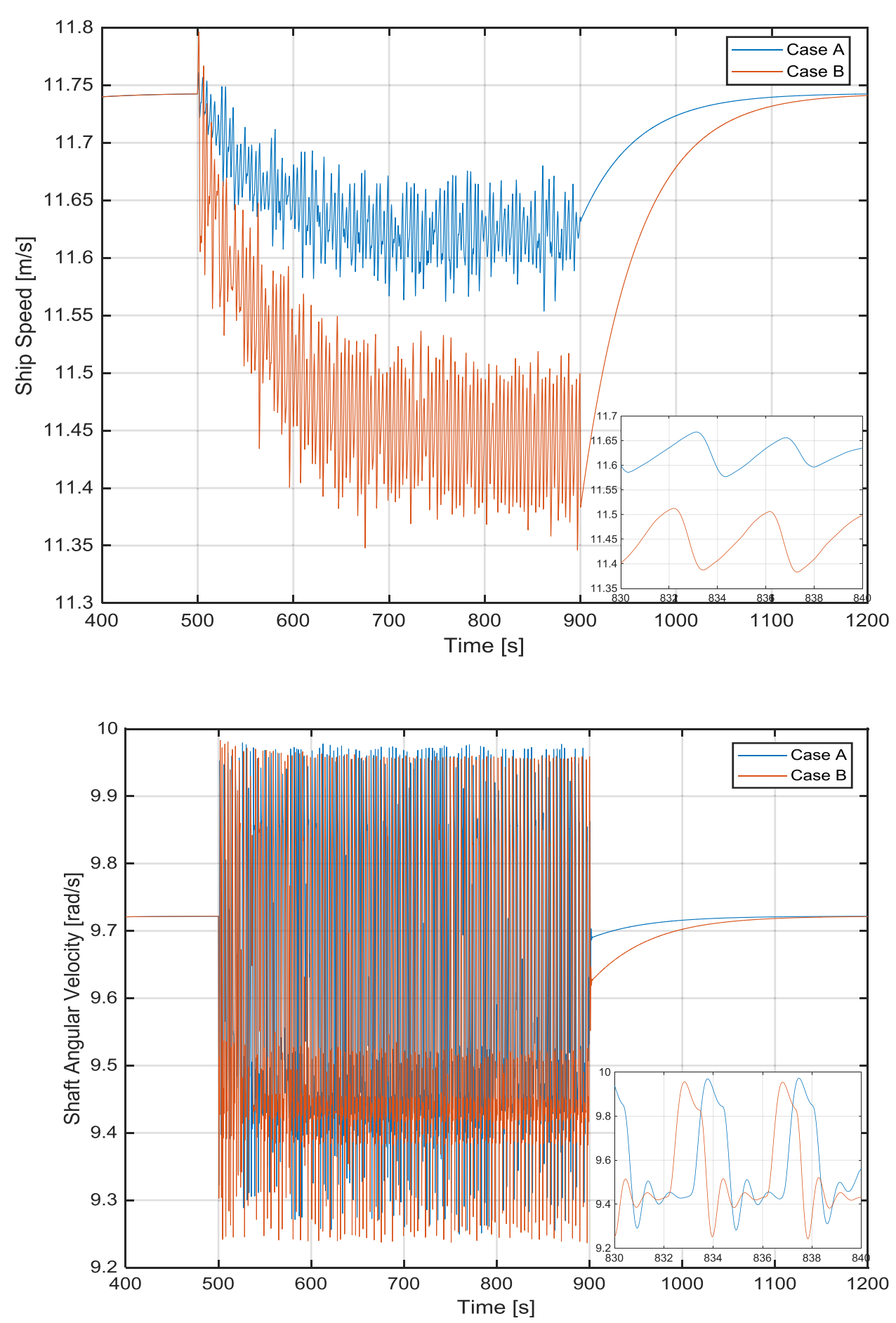

respectively, which in comparison to the calm water effective power $(19,419 \mathrm{~kW})$ are significantly higher.

As a result, when the weather conditions are worse and the height of sea waves increases, the ship propulsion system does not respond linearly. The net thrust and generated power remain in a relatively narrow range and, consequently, the ship's speed reduces despite the governor attempting to maintain the rotational speed of the propeller. Further increases of wave height and wave force mainly cause a reduction of ship speed with no significant influence on the thrust and generated power. It should be noted that fuel consumption increases and the emission level become higher. 
Fig. 8 Time series of net thrust and total resistance for Case A and Case B in sea waves
Fig. 9 Time series of propeller and engine torque for Case $\mathrm{A}$ and Case B in sea waves
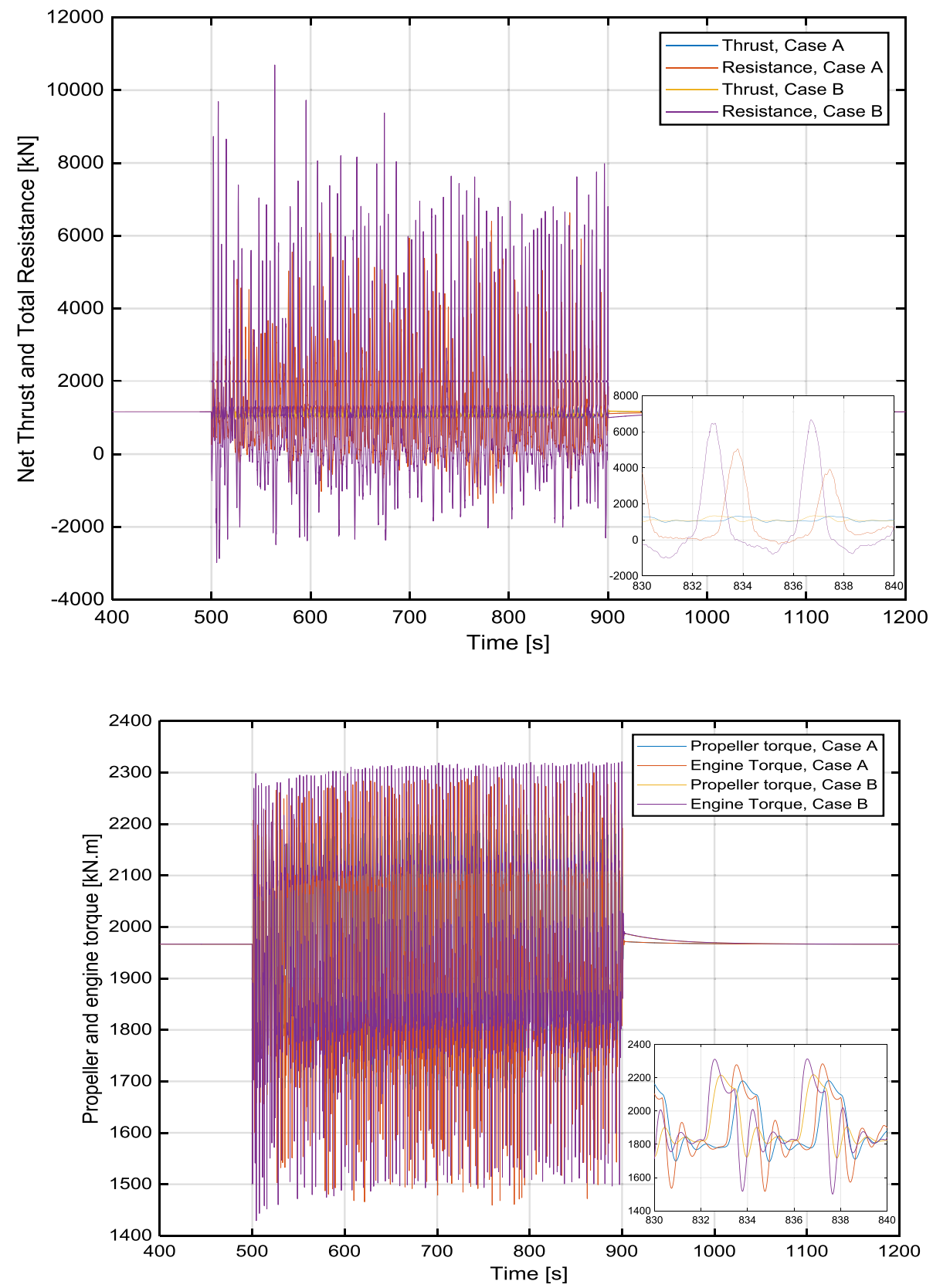

\section{Analysis and discussion}

\subsection{Statistical parameters}

For a periodic sine curve, the mean value is simply zero, either calculated by minima subtracted from maxima or by integrating the area under the curve on the negative side subtracted from the positive side. In case of wave force of non-zero-mean, which is not a pure sine curve, the mean value must be carefully analysed and determined. Here, the mean value was found using a trial and error method to satisfy the following criterion: the closed area between the resistance mean value $\left(\bar{R}_{\mathrm{t}}\right)$ and values lower than the mean value (represented at each time by $R_{\mathrm{t}}^{-}(t)$ ) must be equal to the closed area between the mean value and values greater than the mean value (represented at each time by $R_{\mathrm{t}}^{+}(t)$ ):

$\int_{t_{0}}^{t_{\mathrm{f}}}\left(R_{\mathrm{t}}^{+}(t)-\bar{R}_{\mathrm{t}}\right) \mathrm{d} t=\int_{t_{0}}^{t_{\mathrm{f}}}\left(\bar{R}_{\mathrm{t}}-R_{\mathrm{t}}^{-}(t)\right) \mathrm{d} t$,

where $t_{0}$ is the initial time and $t_{\mathrm{f}}$ is the final time.

Other dynamic responses, such as propeller and engine rotational speeds, thrust, propeller and engine torques and power, have a similar form of fluctuations and their mean 
Fig. 10 Time series of propeller and engine power for Case $\mathrm{A}$ and Case B in sea waves

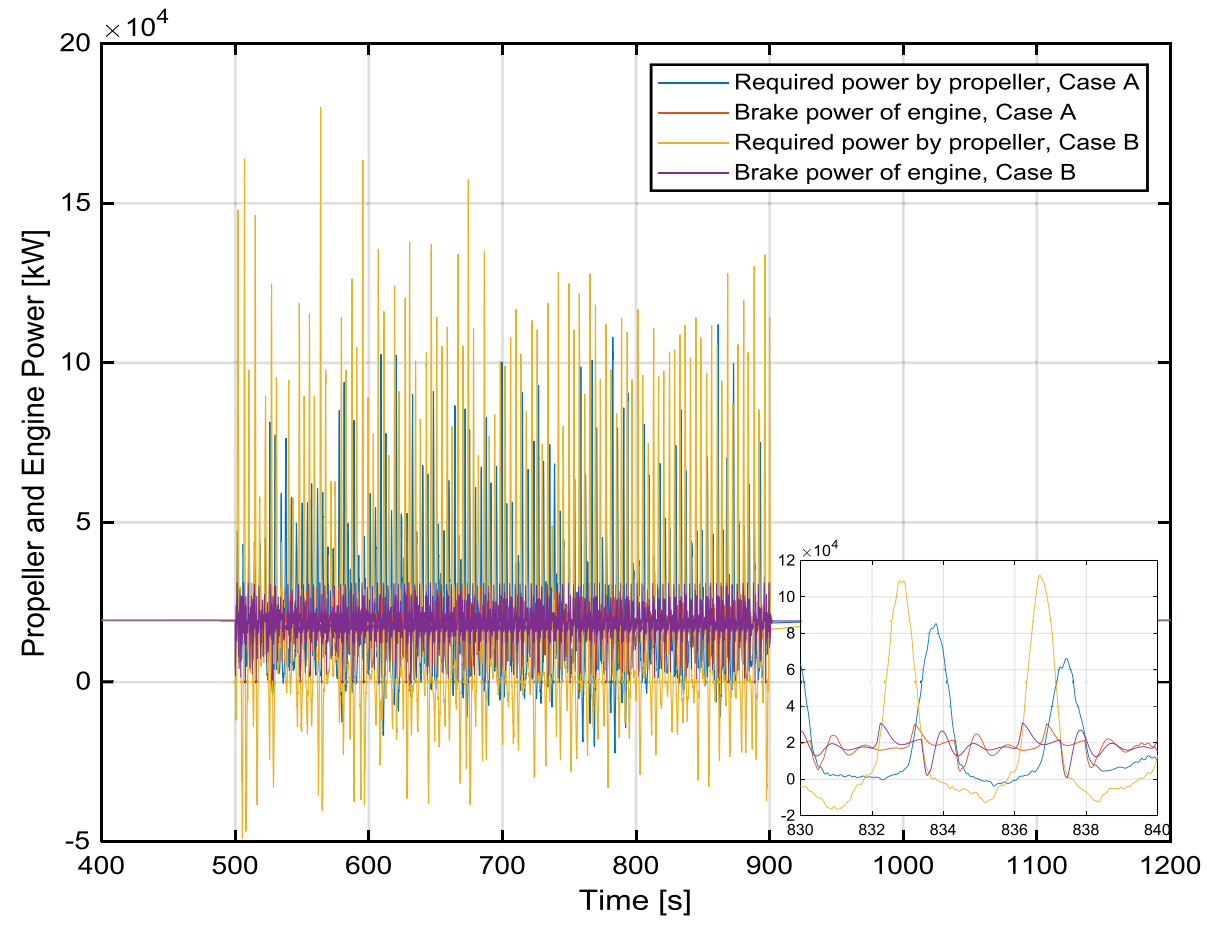

values can be calculated in a similar way. The mean wave force, the added resistance, $\overline{R_{\mathrm{a}}}$, can be treated as follows:

$\overline{R_{\mathrm{a}}}=\overline{R_{\mathrm{t}}}-R_{\mathrm{T}}(u(t))$

Additionally, the added resistance was calculated based on the following relationship for the selected $150 \mathrm{~s}$ :

$R_{\mathrm{as}}=\frac{1}{t_{0}-t_{\mathrm{f}}}\left(\int_{t_{0}}^{t_{\mathrm{f}}} R_{\mathrm{a}}^{2}(t) \mathrm{d} t\right)^{1 / 2}$,

where $t_{0}$ is the initial time and $t_{\mathrm{f}}$ is the final time.

To clarify the range of changes for wave force in comparison to its mean value the wave force variance, $\mathrm{VAR}_{R_{\mathrm{a}}}$, can be calculated as follows:
$\operatorname{VAR}_{R_{\mathrm{a}}}=\frac{1}{t_{\mathrm{f}}-t_{0}} \int_{t_{0}}^{t_{\mathrm{f}}}\left(R_{\mathrm{a}}(t)-\overline{R_{\mathrm{a}}}\right)^{2}$

Here the second phase of simulation (from 500 to $900 \mathrm{~s}$ ) was taken into consideration and the results and signal parameters were determined for the time between 750 and $900 \mathrm{~s}$ (totally $150 \mathrm{~s}$ ) as steady conditions for which the added resistance should be calculated. The results for both transient (the whole $400 \mathrm{~s}$ ) and steady (the selected $150 \mathrm{~s}$ ) are shown in Table 7.

The variances of wave force and total resistance in the whole period of phase two of the simulations yield corresponding values at steady conditions. In both cases, the difference is approximately $10 \%$, which means the total and wave forces fluctuate almost to the same level in transient and steady conditions.
Table 7 Signal parameters of total and wave forces in both transient and steady states

\begin{tabular}{lcccc}
\hline Case and parameter & $\begin{array}{l}\text { Total resistance } \\
R_{\mathrm{t}}(t) \text { for } 400[\mathrm{~s}]\end{array}$ & $\begin{array}{l}\text { Wave force } \\
R_{\mathrm{a}}(t) \text { for } 400 \\
{[\mathrm{~s}]}\end{array}$ & $\begin{array}{l}\text { Total resistance } R_{\mathrm{t}}(t) \\
\text { for the selected } 150[\mathrm{~s}]\end{array}$ & $\begin{array}{l}\text { Wave force } R_{\mathrm{a}}(t) \text { for } \\
\text { the selected } 150[\mathrm{~s}]\end{array}$ \\
\hline $\begin{array}{l}\text { Calm water condition } \\
\text { Mean [kN] }\end{array}$ & 1161.822 & 0.000 & 1161.815 & 0.000 \\
$\begin{array}{l}\text { Case A } \\
\text { Mean [kN] }\end{array}$ & 1187.370 & 25.549 & 1130.637 & 105.566 \\
$\quad$ Variance & & $1,574,427$ & $1,744,675$ & $1,744,674$ \\
Case B & 1279.494 & 117.673 & 1139.857 & 183.342 \\
Mean [kN] & & $5,103,278$ & $5,156,651$ & $5,156,651$ \\
Variance & & & & \\
\hline
\end{tabular}


Table 8 Mean and variance of the ship, propeller and engine variables in calm water and cases A and B

\begin{tabular}{|c|c|c|c|c|c|c|c|c|}
\hline Parameter & $\begin{array}{l}\text { Ship's speed } \\
{[\mathrm{m} / \mathrm{s}]}\end{array}$ & $\begin{array}{l}\text { Propel- } \\
\text { ler speed } \\
{[\mathrm{rad} / \mathrm{s}]}\end{array}$ & Advance number & Net thrust $[\mathrm{kN}]$ & $\begin{array}{l}\text { Propel- } \\
\text { ler torque } \\
{[\mathrm{kNm}]}\end{array}$ & $\begin{array}{l}\text { Engine } \\
\text { torque } \\
{[\mathrm{kNm}]}\end{array}$ & $\begin{array}{l}\text { Effective power } \\
\text { [due to resist- } \\
\text { ance] }[\mathrm{kW}]\end{array}$ & $\begin{array}{l}\text { Brake power } \\
\text { [generated by } \\
\text { engine] }[\mathrm{kW}]\end{array}$ \\
\hline \multicolumn{9}{|l|}{ Calm water } \\
\hline Mean & 11.743 & 9.722 & 0.760 & 1161.8 & 1966.6 & 1966.6 & $19,418.6$ & $19,118.7$ \\
\hline \multicolumn{9}{|l|}{ Case A } \\
\hline Mean & 11.623 & 9.615 & 0.761 & 1136.3 & 1923.4 & 1922.9 & $18,905.1$ & $18,517.3$ \\
\hline Variance & $0.00,055$ & $0.04,315$ & $0.00,028$ & 10,335 & 22,817 & 34,862 & $493,277,058$ & $19,785,731$ \\
\hline \multicolumn{9}{|l|}{ Case B } \\
\hline Mean & 11.443 & 9.560 & 0.753 & 1145.7 & 1930.3 & 1930.3 & $19,071.1$ & $18,489.6$ \\
\hline Variance & 0.0017 & 0.04370 & $0.00,029$ & 10,685 & 23,412 & 37519. & $1,433,430,400$ & $26,844,394$ \\
\hline
\end{tabular}

Table 9 Fuel consumed during $t=500$ to $t=900 \mathrm{~s}$

\begin{tabular}{llc}
\hline Condition & Dimension & Value \\
\hline Calm water & {$[\mathrm{kg}]$} & 351.518 \\
Case A & {$[\mathrm{kg}]$} & 352.476 \\
Case B & {$[\mathrm{kg}]$} & 363.546 \\
Case A vs. calm water & {$[\mathrm{kg}]$} & +0.958 \\
Case B vs. calm water & {$[\mathrm{kg}]$} & +12.029 \\
$\begin{array}{l}\text { Relative increase (Case A - calm } \\
\text { water)/(calm water) }\end{array}$ & {$[\%]$} & $0.27 \%$ \\
$\begin{array}{l}\text { Relative increase (Case B - calm } \\
\text { water)/(calm water) }\end{array}$ & {$[\%]$} & $3.42 \%$ \\
\hline
\end{tabular}

Seven system variables were selected as system outputs and their signal parameters are given in Table 8. The selected variables are ship speed, shaft rotational speed, advance number, net thrust, propeller torque, engine torque, effective power and engine generated brake power. The mean and variance of each variable were calculated similarly as given for the wave force (see Eqs. 26 and 27). The initial and final times were selected as before to be able to compare different values in calm water with both cases $\mathrm{A}$ and $\mathrm{B}$.

\subsection{Discussion}

The ship's speed mean value decreased from 11.74 in calm water to 11.62 and $11.44 \mathrm{~m} / \mathrm{s}$ in Case A and Case B, respectively. Despite large fluctuations of wave force in both cases, the added resistance was not too high to significantly affect the ship's speed, if the engine rotational speed was maintained at an almost constant level by the governor.

To check the environmental and economic effect of the selected voyage mode, the fuel consumed in calm water conditions, Case A and Case B, was calculated using the steady-state characteristics of the engine provided by the manufacturer (see Table 5). The results are shown in Table 9. When the conventional engine control law was
Table 10 Travelled distance and average ship's speed

\begin{tabular}{llllll}
\hline & \multicolumn{2}{c}{ Travelled distance } & & \multicolumn{2}{c}{$\begin{array}{l}\text { Average ship's } \\
\text { speed }\end{array}$} \\
\cline { 2 - 3 } \cline { 5 - 6 } \cline { 5 - 6 } & Unit & Distance & & Unit & Speed \\
\hline Calm water & $\mathrm{m}$ & 4697.139 & $\mathrm{~m} / \mathrm{s}$ & 11.743 \\
Case A & $\mathrm{m}$ & 4655.750 & & $\mathrm{~m} / \mathrm{s}$ & 11.639 \\
Case B & $\mathrm{m}$ & 4593.793 & & $\mathrm{~m} / \mathrm{s}$ & 11.484 \\
Case A vs. calm water & $\mathrm{m}$ & -41.389 & $\mathrm{~m} / \mathrm{s}$ & -0.103 \\
Case B vs. calm water & $\mathrm{m}$ & -103.346 & $\mathrm{~m} / \mathrm{s}$ & -0.258 \\
Relative increase (Case & $\%$ & $-0.88 \%$ & $\%$ & $-0.88 \%$ \\
$\begin{array}{l}\text { A - calm water)/(calm } \\
\text { water) }\end{array}$ & & & & \\
$\begin{array}{l}\text { Relative increase (Case } \\
\text { B - calm water)/(calm }\end{array}$ & $\%$ & $-2.20 \%$ & $\%$ & $-2.20 \%$ \\
water) & & & & \\
\hline
\end{tabular}

applied and governor tries to keep the rotational speed of the engine at a constant level the consumed fuel increases by $0.3 \%$ and $3.4 \%$ with respect to calm water for Case A and Case B, respectively, which shows how the sea wave heights influence the consumed fuel even though necessary large variations of fuel index are not permitted using limiters in the governor. The above fuel rate increase is directly connected to the kind of applied limiters (for torque and fuel rate), other kinds of limiters may cause a larger increase in fuel rate.

The above analysis does not include the speed loss during operation in sea waves. To include the ship's speed loss, the distance travelled by the ship under sea waves during $400 \mathrm{~s}$ is shown in Table 10 and compared with calm water. In Case A and Case B, the travelled distance with respect to calm water is reduced by $1 \%$ and $2.2 \%$, respectively, due to speed loss. The table also includes the average ship speed calculated by dividing the travelled distance over time.

Taking Tables 9 and 10 into account, the average rate of fuel consumed per kilometre was calculated and given in Table 11. The wave in Case A causes an increased fuel 
Table 11 Consumed fuel per kilometre

\begin{tabular}{llc}
\hline & Dimension & Value \\
\hline Calm water & $\mathrm{kg} / \mathrm{km}$ & 74.837 \\
Case A & $\mathrm{kg} / \mathrm{km}$ & 75.708 \\
Case B & $\mathrm{kg} / \mathrm{km}$ & 79.139 \\
Case A vs. calm water & $\mathrm{kg} / \mathrm{km}$ & 0.871 \\
Case B vs. calm water & $\mathrm{kg} / \mathrm{km}$ & 4.302 \\
Relative increase (Case A - calm & - & $1.16 \%$ \\
$\quad$ water)/(calm water) & & \\
$\begin{array}{l}\text { Relative increase (Case B - calm } \\
\text { water)/(calm water) }\end{array}$ & - & $5.75 \%$ \\
\hline
\end{tabular}

consumption of $1.16 \%$ with respect to calm water, while the respective level for Case B is 5.75\%.

\section{Conclusions}

In this study, experimental data for calm water, wave force and open water propeller performance as well as engine characteristics provided by the manufacturer, were employed in a mathematical model, which was then used for simulation in the time domain. The purpose was analysing the system response under sea waves including interactions between the hull, propeller and engine. The analysis was provided for a container ship and two regular waves of $1.63 \mathrm{~m}$ and $3.23 \mathrm{~m}$ wave height. The outcomes of the analysis can be concluded as follows:

- Conventional method based on the mean value of added resistance for calculation of speed reduction disregards many dynamic behaviours. A rational method should include time series fluctuations of such variables like as wave force, ship speed, propeller rotational speed, engine torque and power and so on.

- The results for the studied cases show that even by applying torque and fuel rate limiters, the fuel consumption still is strongly a nonlinear function of sea wave parameters.

- The propeller hydrodynamic performances are non-linearly varying by increasing the wave height. The nonlinearity is amplified also by diesel engine dynamics controlled by the governor.

- The presented approach may be further utilized for fuel consumption optimization in sea waves. It may also be implemented for the engine subsystem maintenance planning through fatigue analysis in real sea conditions.
Open Access This article is licensed under a Creative Commons Attribution 4.0 International License, which permits use, sharing, adaptation, distribution and reproduction in any medium or format, as long as you give appropriate credit to the original author(s) and the source, provide a link to the Creative Commons licence, and indicate if changes were made. The images or other third party material in this article are included in the article's Creative Commons licence, unless indicated otherwise in a credit line to the material. If material is not included in the article's Creative Commons licence and your intended use is not permitted by statutory regulation or exceeds the permitted use, you will need to obtain permission directly from the copyright holder. To view a copy of this licence, visit http://creativecommons.org/licenses/by/4.0/.

\section{References}

1. Schulten PJM (2005) The interaction between diesel engines, ship and propellers during manoeuvring, $\mathrm{PhD}$ Thesis, Delft, available on marin.nl

2. Lanchukovsky VI (2009) Safe operation of marine power plants, marine engineering practice series. IMarEST, London

3. Bondarenko O, Kashiwagi M (2010) Dynamic behaviour of ship propulsion plant in actual seas. Mar Eng 45:1012-1016. https://doi. org/10.5988/jime.45.1012

4. Kayano J, Yabuki H, Sasaki N, Hiwatashi R (2013) A Study on the propulsion performance in the actual sea by means of full-scale experiments. TransNav Int J Mar Navig Saf Sea Transp 7(4):521526. https://doi.org/10.12716/1001.07.04.07

5. Tanizawa K, Kitagawa Y, Takimoto T, Tsukada Y (2013) Development of an experimental methodology for self-propulsion test with a marine diesel engine simulator. Int J Offshore Polar Eng 23(3):197-204

6. Theotokatos G, Tzelepis V (2015) A computational study on the performance and emissions parameters mapping of a ship propulsion system. J Eng Marit Environ 229(1):58-76

7. Taskar B, Yum KK, Steen S, Pedersen E (2016) The effect of waves on engine-propeller dynamics and propulsion performance of ships. Ocean Eng 122:262-277. https://doi.org/10.1016/j.ocean eng.2016.06.034

8. Tokgoz E, Wu P-C, Takasu S, Toda Y (2017) Computation and experiment of propeller thrust fluctuation in waves for propeller open water condition. J Jpn SocNaval Arch Ocean Eng 25:55-62

9. Mizythras P, Boulougouris E, Theotokatos G (2018) Numerical study of propulsion system performance during ship acceleration. Ocean Eng 149:383-396. https://doi.org/10.1016/j.ocean eng.2017.12.010

10. Kitagawa $Y$ et al (2019) An experimental method to identify a component of wave orbital motion in propeller effective inflow velocity and its effects on load fluctuations of a ship main engine in waves. Appl Ocean Res. https://doi.org/10.1016/j.apor.2019.101922

11. Zeraatgar H, Ghaemi MH (2019) The analysis of overall ship fuel consumption in acceleration manoeuvre using hull-propeller-engine interaction principles and governor features. Pol Mar Res 26:101. https://doi.org/10.2478/pomr-2019-0018

12. Lewandowski EM (2004) The dynamics of marine craft, manoeuvring and seakeeping. World Scientific, $\mathrm{p} 22$

13. Liu S, Papanikolaou A, Zaraphonitis G (2011) Prediction of added resistance of ships in waves. Ocean Eng 38(4):641-650. https://doi. org/10.1016/j.oceaneng.2010.12.007

14. MacPherson DM, Puleo VR, Packard MB (2007). Estimation of entrained water added mass properties for vibration analysis. In: SNAME New England Section, 2007

15. Saunders HE (1957) Hydrodynamics in ship design. SNAME, New York 
16. Veritec (1985) Vibration control in ships, Høvik, Norway: A.S. Veritec Marine Technology Consultants, Noise and Vibration Group, ISBN: 9788251500906

17. Domachowski Z, Ghaemi MH (2007) Marine control systems (Okrętowe układy automatyki, in Polish), Publication of Gdańsk University of Technology, ISBN $9788373481770837348177 X$
18. Ghaemi MH (2011) Changing the ship propulsion system performances induced by variation in reaction degree of turbocharger turbine. J Pol CIMAC 6:55-70

Publisher's Note Springer Nature remains neutral with regard to jurisdictional claims in published maps and institutional affiliations. 